\title{
The model of development of a professional competence of future teachers on the basis of a personality-centered approach
}

\author{
L.I. Abbasova ${ }^{1 *}$ \\ ${ }^{1}$ State Budget Educational Institution of Higher Education of the Republic of Crimea Crimean \\ Engineering and Pedagogical University the name of Fevzi Yakubov, Simferopol, Russia
}

\begin{abstract}
The article describes specific features of the development of professional competence of future teachers. The development of the professional competence of future teachers on the basis of the personalitycentered approach is aimed at changing personal readiness for the process of implementing their future professional and pedagogical activities. Different views of scientists on the definition of "professional competence" are considered. The model of developing personal and professional competence of future teachers is presented, which consists of four components: target; content-organizational; diagnostic and reflexiveprognostic component. The main forms of work with students within the framework of the presented model are interactive technologies for conducting classes, consisting of four components: target; contentorganizational; by means of facilitating the processes of self-actualization and self-development, etc. An important role is given to individual work with students, pedagogical support in building individual routes for each future teacher. Independent activity presupposes work on one's own personality, with one's own inner world for the purpose of selfimprovement and use of the Self-Observation Diary. The knowledge and experience gained are further implemented as a result of practical training of students at the bases of specialized organizations. The results of experimental activities on the implementation of the model of development of professional competence of future teachers in practice are described.
\end{abstract}

\section{A problem statement}

In connection with the rapidly occurring significant socio-economic changes, modern society needs a qualitatively new subject of pedagogical activity - a professionally competent and self-actualizing personality, focused on continuous self-education, with developed creative and professional thinking. Modernization of education on a competencebased basis requires essential changes in all links of the pedagogical system as the integrity, renewal and humanization of the educational process.

\footnotetext{
* Corresponding author: prof-ped.gpa@mail.ru
} 
The development of personal and professional competence of future teachers on the basis of a personality-centered approach to teaching can contribute to implementation of the competence-based approach and humanization of the educational process at a university, preparation of a new subject of pedagogical activity in general. The personality-centered approach is the most consistent approach of the humanistic direction in pedagogical science, according to it, a person is the subject of his own development, a responsible center and the main factor in human life creation.

\subsection{The objective of the work}

Improving the quality of education is one of the priority tasks of the modern society. Assistance in solving the indicated problem can be provided by the priority focus of modern education on the personal growth of students, the development of their potential, subjectivity, and creative self-realization in general.

According to O.V. Kisel, A.I. Dubskikh, A.N. Butovoy, personality-centered education requires a greater individualization of the pedagogical process, taking into account the interests, meanings and needs of students, greater variety and fun of learning, strengthening the creative component [1].

The implementation of personality-centered learning presupposes introduction of certain changes into the professional training of future teachers. Such changes are primarily related to increasing teachers' personal readiness to carry out professional and pedagogical activities (Robert M. Klassen, Lisa E. Kim, Jade V. Rushby, Lisa Bardach [2]).

In the process of reforming educational system, the result of student learning began to be considered as the level of development of their professional competence, professional and social self-determination (N.Yu. Belikova, E.Yu. Ponomareva et al. [3]).

Scientists A.A. Kutumova, A.K. Alekseevnina and others [4] indicate that a future teacher can effectively contribute to personal growth, meaningful and internally motivated learning, the development of students as creative individuals, he himself needs to possess a developed professional competence, implying a high level of self-actualization and pedagogical competence.

In the process of analyzing the state of the problem of developing the professional competence of future teachers, we came across works devoted to the development of this type of competence in the higher educational system: the development of professional competencies of future engineers (M.A. Zubkova M.A., N.Yu. Fominykh, etc. [5]); development of professional competence of psychology teachers in a university environment (T. Yessimgaliyeva, A. Ageleuova, etc. [6]), development of professional competencies of specialists trained for organizations of the national economy of the Russian Federation (E.L. Kruglova [7]), development of professional communicative competence of teachers in subject communication with students (E.N. Belous [8]), the formation of psychological and pedagogical competence of young teachers (N.F. Ilyina [9]).

In addition, in the course of the analysis, we found studies aimed at developing the professional competence of future specialists in other professional fields, for example: the development of personal and professional competence of future teachers as a condition of the humanistic paradigm of education (E.V. Vesetiu [10]); the formation of a foreign language professional and communicative competence among students of a pedagogical university by means of CLIL - Content and Language Integrated Learning (O.G. Byrdina, E.A. Yurinova [11]), preparation of future teachers for the formation of social and communicative competence of preschoolers (I.V. Zotova, O.Yu. Butvina [12]). This, in our opinion, speaks of the high importance and relevance of this type of competence both for 
teachers (in their daily pedagogical practice) and for the socio-economic development of the country as a whole.

\section{Results of the research}

The development of a professional competence, along with the development of the personality of a future teacher, is the main task of realizing the competence of his of her approach in higher pedagogical education.

According to M. Blašková [13], although these concepts are close, they are not identical. In the hierarchical structure of these terms, professional and pedagogical competence occupies a middle position. "Professional competence is a qualitative characteristic of a subject, acquired by him in the process of vocational training. As a result of labor activity, it is gradually transformed into professionalism, which is a high skill, characterizes a deep mastery of the teaching profession and is expressed in the ability to creatively use the information acquired in the learning process".

So, according to K.A. Moronov [14], the professional and personal competence of a teacher is a complex of states and personality traits that make it possible to successfully solve professional problems in training and education.

Researchers N.A. Kazachenko and others [15] distinguish the following invariant features of the teacher's professional and personal competence:

- motivated striving for continuous professional self-improvement;

- an ability for a systemic vision of pedagogical reality and systemic action in a professional pedagogical situation;

- an ability to find non-standard solutions to professional and pedagogical problems;

- a tendency to professional reflection;

- possession of a system of professional and moral values and priorities.

Here, according to Chuanjing $\mathrm{Ju}$ [16], the following should be noted, since the specifics of professional activity, according to most scientists, depends on the personality traits, qualities and properties of the teacher, the logical structure of this concept, namely "personal and professional competence", can be considered quite legitimate.

According to I.V. Gavrilova [17], professional competence is a structural and integrative property, including a peculiar content of values and personal qualities that ensure the effectiveness of activities in the professional sphere, as well as an awareness of social significance, personal responsibility for the results of one's activities and the need for its constant improvement.

Thus, according to I. Aryabkina [18], the basis of the personality-centered approach is formed by personality traits of a teacher who is self-actualizing and capable of selfdevelopment in his or her professional activity.

In addition, teacher's personality-centered approach is characterized by active selfpositing in the profession, self-knowledge, self-expression and self-improvement in it (S. Kaldi, E. Xafakos [19]); humanistic outlook of the teacher (A. Ruelens, I. Nicaise [20]). In the studies of K. Gliske, J. Ballard, G. Buchanan [21] and others, the personality-centered approach presupposes the following: I-personality image as a professional teacher; finding personal meanings, value orientations and interests in the field of professional activity; need to grow in the profession, to improve professional competence and professionalism, to more effectively solve professional problems.

The analysis of elaboration degree of the problem of the development of a professional competence of future teachers allowed us to conclude that the pedagogical model of the development of this competence on the basis of a personality-centered approach remains insufficiently studied. 
Before proceeding to the description of the model worked out by us and devoted to the development of personal and professional competence of future teachers, it is necessary to clarify the indicators that determine the development level of this competence of a teacher.

The above analysis of scientific and pedagogical works allowed us to reveal that the level of development of the personal and professional competence of future teachers in the educational process of the university can be determined using indicators such as the development of their inter- and intrapersonal competencies (I.N. Odarich, M.I. Gavrilova [22]).

Having determined the levels of revealing a teacher's professional competence and the indicators of its development, we proceed to describe the model for the development of a professional competence of future teachers, developed by us on the basis of a personalitycentered approach.

In order to work out pedagogical aspects of the development of a professional competence of future teachers, we have chosen a modeling method. Thus, according to V.I. Blinov and I.S. Sergeev [23], it allows us to consider the pedagogical process as an integrative, holistic phenomenon and to present the connections between its individual components.

The model reflects our ideas about an effective organization of the educational process at the university in order to develop personal and professional competence of students and consists of four components: target; content-organizational; diagnostic and reflexiveprognostic component.

Let us consider each component of the model in detail.

The target component includes the following: the goal, objectives and basic principles of the process under consideration. At the same time, we proceeded from the analysis of the essence of professional competence and the characteristics of its development within future teachers on the basis of a personality-centered approach.

The purpose of building the model is to develop professional competence of future teachers on the basis of a personality-centered approach. To achieve it, the following tasks were formulated:

Facilitation of professional development and self-development of future teachers, including the following:

- providing teachers with psychological and pedagogical assistance and support in selfactualization and self-development;

- rendering assistance to future teachers in the development of inter- and intrapersonal competences of a teacher;

- providing teaching assistance in the development of a system of knowledge, concepts and ideas about the main psychological and pedagogical directions of modern education;

- the one concerning the problems of the inner world of a person, his self-actualization and self-development; support for their choice of "their" personal and professional world outlook position.

Implementation of the selected pedagogical conditions in the higher educational process, contributing to the development of professional competence of future teachers, is considered.

Based on the research of L.V. Boer [24], the following principles of the model were identified as basic ones:

- recognition of a future teacher as the subject of his or her own personal and professional development;

- taking into account individual psychological and cross-cultural (family, religious, national, etc.) characteristics of a future teacher;

- ensuring voluntary, free personal and semantic inclusion of future teachers in educational activities aimed at developing professional competence; 
- problematic content of training sessions;

- recognition of the leading role of joint activity, interpersonal interaction and dialogical communication of the subjects of educational process.

The next component of the model is the content-organizational one. The main place in it is occupied by pedagogical conditions, the implementation of which in the higher educational process will ensure the achievement of the set goal:

Wider use of interactive work forms with students. In this regard, we have compiled theoretical and practical interactive classes involving the development of professional competence of future teachers, through the facilitation of the processes of self-actualization and self-development. Lectures were conducted in the following forms: lectureconversation; lecture-discussion; problem lecture; lecture with analysis of specific situations. In the practical part of the classes, we included training for the development of professionally significant personality traits and interactive seminars, namely: brainstorming; round table; business and role-playing game.

Providing assistance to future teachers in the development and implementation of an individual educational route at the university. To implement this condition, we selected the types of individual educational routes, which, according to M.A. Kunash [25], S.A. Kotova [26], can be offered to future teachers in the educational process of the university, and also made up a program of pedagogical support for their implementation.

In order to develop the professional competence of future teachers, the following types of individual educational routes were selected:

- "I myself am a centered educational route". This route is based on the personality of the student, his personal meanings, cognitive interests, desires and needs. The route has a pronounced focus on the student's personal growth. The chosen disciplines are focused mainly on the satisfaction of the student's personal rather than professional educational needs (acquiring knowledge, developing qualities and skills that contribute primarily to the development of a future teacher as a mature, erudite personality, cultural, educated person);

- "a professionally centered educational route". It is based on a clear and definite goal of a future teacher. Individual educational routes have a pronounced professional focus. The chosen disciplines are focused on the development of a professional competence, the acquisition of knowledge and experience, the development of professionally important qualities and skills that allow the future teacher to fulfill his professional duties with dignity, at a high level;

- "a science-centered educational route". This route is based on the desire and aspirations of a future teacher to become a professional scientist. Individual educational routes are focused on scientific activity, further admission to the magistracy. The chosen disciplines are associated with the acquisition of knowledge and experience in practical research activities, as well as providing the student with the opportunity to engage in a field of interest in science.

The pedagogical support program consists in providing future teachers with the necessary information and advisory assistance in the selection, development and implementation of individual educational routes in higher education.

Organization of groups of free communication or "group meetings" is determined to assist in the independent pedagogical creativity of students, help and support their personal growth and pedagogical professionalism in general. The main task in the implementation of this condition is to create a favorable psychological climate. Free communication groups can be made up of students of different courses and different pedagogical specialties. Lecturers from different departments, guest-experts, specialists in the socio-cultural sphere can be invited to the "meetings". In the process of such "meetings", certain topics, facts and urgent problems are discussed together; students have the opportunity to present the results of both individual and collective creativity (development of projects, models, programs; 
own pedagogical compositions: abstracts; articles; essays, various stories and poems; just share their ideas, considerations in the field of pedagogy and psychology); get a group consultation from a teacher or an expert on issues of interest.

Providing future teachers with independent work focused on personal and professional growth is another significant aspect. A feature of the implementation of this condition is that students mostly work not with teaching aids or scientific literature, but on their own personality, with their own inner world in order to improve themselves.

Also, a feature of this condition is keeping by future teachers the "Diary of introspection", in which they record the ongoing changes in the development of personal and professional competence; the results of self-analysis, reflection of one's behavior and the characteristics of learning process in higher education; ideas about personal and professional future. The number of hours required for independent work is determined by the future teacher himself. Based on the results of the independent work, at the end of the semester, the student submits a resume in a free form.

Providing future teachers on an elective basis with pedagogical practices that allow them to develop their own personal and professional competence in the conditions of real pedagogical activity is the next key factor. To implement this condition, we have developed and agreed with the Department of Preschool Pedagogy and Pedagogy of the Crimean Engineering and Pedagogical University named after Fevzi Yakubov a set of practical pedagogical tasks, in our opinion, allowing teachers to check, evaluate and develop professionally significant personality traits, knowledge and skills, components of the teacher's personal and professional competence. The practical tasks offered to choose from serve as an addition to the compulsory pedagogical practice of students in educational institutions.

Thus, the implementation of the pedagogical conditions we have identified can occur: in optional disciplines; a set of tasks for independent work and pedagogical practice of students.

The next component of the model for the development of professional competence of future teachers is diagnostic. This component involves the definition of a procedure for assessing the results, diagnosing the level of development of professional competence of future teachers; selection of methods and techniques for measuring this competence.

The last component of the model is a reflective-predictive one. This component, based on the interpretation and analysis of the results obtained, involves making adjustments to the content and organization of the process of developing the personal and professional competence of future teachers. In this regard, it is allowed to work out and build a new prognostic model for the development of this competence, corresponding to the new level of self-actualization and self-development, the stage of students' personal growth and the cyclical nature of the pedagogical process.

Testing the effectiveness of the model for the development of professional competence of future teachers on the basis of a person-centered approach involves conducting primary (revealing the initial level of development of professional competence of future teachers) and final (determining the level of development of professional competence at the end of model testing) diagnostics in the control and experimental groups of students.

In the context of the development of professional competence, the pedagogical potential of the personality-centered approach is to provide future teachers with the following opportunities:

- to individualize to a greater extent the process of professional training, by creating pedagogical conditions that are more responsive to the personality characteristics of students; 
- assistance in the development of students' subjectivity, through the priority focus of the learning process on personal growth and self-determination, their personal meanings and interests;

- assistance in the personal and professional growth of future teachers, through the development of professionally significant personality traits, knowledge and skills that contribute to self-actualization and self-development.

The dynamics of the development levels of the professional competence of future teachers based on the personality-centered approach is shown in Figure 1.

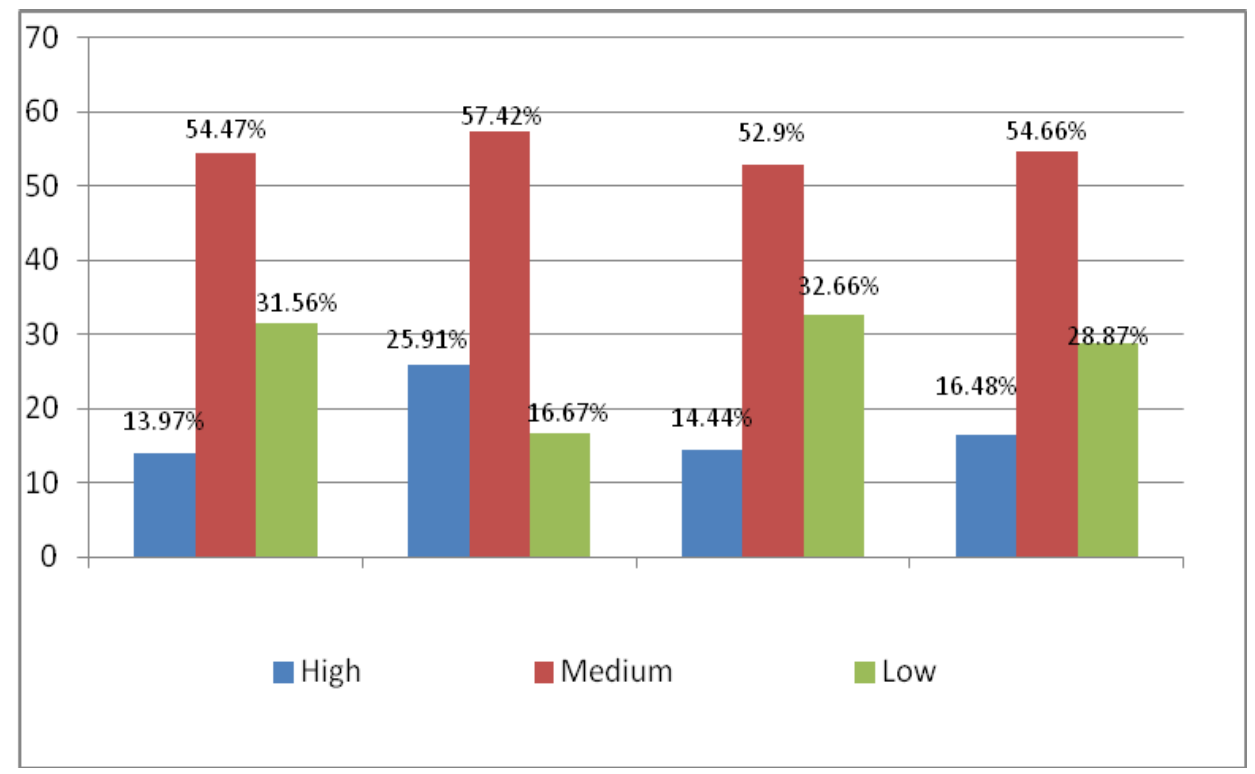

Fig. 1. Comparative results of the development levels of professional competence of future teachers based on the personality-centered approach.

Comparative quantitative results presented in Figure 1 indicate positive dynamics in the development of a professional competence of future teachers based on a personalitycentered approach. So, at the ascertaining stage of the experiment, a high level of development of professional competence was observed in $13.97 \%$ of the respondents in the experimental group, and after the formative experiment, their number increased to $25.91 \%$. There was an increase in the number of students with an average level of development of professional competence of future teachers from $54.47 \%$ at the stage of ascertaining to $57.42 \%$ at the control stage. The percentage of future teachers with an initially low level of development of professional competence of future teachers on the basis of a personalitycentered approach decreased from $31.56 \%$ to $16.67 \%$.

Less significant changes occurred among the respondents in the control group: the number of respondents who were at a high level increased from $14.44 \%$ to $16.48 \%$, on average - from $52.9 \%$ to $54.65 \%$, at a low level decreased from $32.66 \%$ up to $28.87 \%$.

The analysis of the results of the final diagnostics of the level of development of professional competence of future teachers allows us to conclude that the experimental work on the implementation in the educational process of the organizational and pedagogical conditions for the development of this competence of students, which we have identified, ended with positive results. In turn, the positive results obtained indicate their effectiveness, and hence the effectiveness of the model for the development of professional competence of future teachers worked out on the basis of a personality-centered approach. 
After interpreting and analyzing the results obtained, we moved on to the reflexiveprognostic component of the model for the development of professional competence of future teachers. This component involves carrying out scientific reflection on the process of implementing the organizational and pedagogical conditions for the development of this competence and making the necessary adjustments to the model.

Since, in general, the implementation of the selected conditions ended with positive results, we considered it inappropriate to make significant adjustments to the developed model. In order to continue the work aimed at developing the personal and professional competence of students next year, we decided to limit ourselves to the following additions:

- development of new tasks for interactive theoretical and practical lessons; for independent work and teaching practice of students; composing new topics and inviting new guests.

In new assignments, pay special attention to such problems as:

- psychological and pedagogical foundations of building dialogical communication with the subjects of the educational process;

- practical ways of facilitating the educational and educational activities of students and their personal growth;

- the basics of designing and developing individual education, training and development programs for pupils;

- invitation of senior students to give lectures together on the topics chosen by them, as well as their participation in round tables, brainstorms together with junior students;

- conducting interactive classes with students of different pedagogical specialties;

- providing, within the framework of the student scientific laboratory, advisory and methodological assistance to young specialists, graduates of higher education.

\section{Conclusions}

The study revealed the pedagogical potential of the personality-centered approach in the context of development of a professional competence, which consists in providing future teachers with the following opportunities: to individualize the process of vocational training to a greater extent, by creating pedagogical conditions that take into account the personality characteristics of students; assistance in the development of the subjectivity of future teachers, through the priority focus of the learning process on personal growth and selfdetermination, personal meanings and interests of students; assistance in the personal and professional growth of future teachers, through the development of professionally significant personality traits, knowledge and skills that contribute to self-actualization and self-development in professional activities.

The positive results obtained from the experimental testing of the model for the development of professional competencies of future teachers confirmed the validity of choosing a personality-centered approach as a methodological basis for solving the problem under study.

\section{References}

1. O.V. Kisel, A.I. Dubskikh, A.V. Butova, Difficulties in applying the student-centered approach in Russian higher education "Higher education in Russia", Teaching and Teacher Education, 8-9, 95-103 (2020)

2. R.M. Klassen, L.E. Kim, J.V. Rushby, L. Bardach, Can we improve how we screen applicants for initial teacher education?, Teaching and Teacher Education, 87, 11-13 (2020) 
3. N.Yu. Belikova, E.U. Ponomareva, V.V. Kotlyarova, S.V. Yushina, L.I. Abbasova, A.T. Latysheva, Professional and social self-determination of youth under conditions of the modernization of higher education, Revista Genero e Direito, 9(4), 846-859 (2020)

4. A.A. Kutumova, A.K. Alekseevnina, N.S. Buslova, N.V. Zybina, Features of vocational training methodology in a pedagogical university, The world of science, culture, education, 4(65), 25-28 (2017)

5. M.A. Zubkova, N.Yu. Fominykh, E.N. Baranova, L.I. Abbasova, A.O. Pirozhkova, A.V. Bubenchikova, Sh.M. Maigeldieva, Approaches to the future engineers foreign communicative culture formation, Humanities and Social Sciences Reviews, 7(4), 781-786 (2019)

6. T. Yessimgaliyeva, A. Ageleuova, A. Beisenbayeva, K. Zhansugurova, A. Zhorabekova, Forming diagnostic competence of psychology teachers in a university setting, Thinking Skills and Creativity, 38, 10-12 (2020)

7. E.L. Kruglov, Assessment of the professional competence of specialists trained for organizations of the national economy of the Russian Federation, University Bulletin, 1, 148-155 (2021)

8. E.N. Belous, M.A. Erofeeva, Features of professional communicative competence of teachers in subject communication with students, Perspectives for Science and Education, 4(40), 126-140 (2019)

9. N.F. Ilyina, N.F, Loginova. Study of the formation of psychological and pedagogical competence of young teachers, Education Issues, 4, 202-230 (2019)

10. E.V. Vesetiu, Formation of facilitative competence of future teachers as a condition of the humanistic paradigm of education, Problems of modern teacher education, 62(1), 80-82 (2019)

11. O.G. Byrdina, E.A. Yurinova, S.G. Dolzhenko, Formation of foreign language professional and communicative competence among students of a pedagogical university by means of clil., Education and Science, 22(7), 77-100 (2020)

12. I.V. Zotova, O. Yu. Butvina, Preparing future educators for the formation of social and communicative competence of preschoolers, Modern teacher education, 4, 111$113(2020)$

13. M. Blašková, R. Blaško, A. Kucharčíková, Competences and Competence Model of University Teachers. Procedia, Social and Behavioral Sciences, 159(23), 457-467 (2014)

14. K.A. Mornov, O.L. Podlinyaev, Pedagogical conditions for the development of personal and professional competence of future teachers, Bulletin of the Buryat State University. Education. Personality. Society, 1, 118-125 (2013)

15. N.A. Kazachenko, L.V. Naydenova, V.V. Bukatov, The student's educational activity as an indicator of the effectiveness of the development of professional competence, Modern teacher education, 2, 74-77 (2021)

16. Ju. Chuanjing, Work motivation of safety professionals: A person-centered approach, Safety Science, 127, (2020)

17. M.I. Gavrilova, I.N. Odarich, Professional competence of a bachelor, Azimuth of Scientific Research: Pedagogy and Psychology, 1(10), 22-23 (2015)

18. I. Aryabkina, Pedagogical Model of Primary School Teacher Cultural and Aesthetic Competence Formation Using Personality Oriented Approach, Procedia-Social and Behavioral Sciences, 214, 10-17 (2015) 
19. S. Kaldi, E. Xafakos, Student teachers' school teaching practice: The relation amongst perceived self-competence, motivation and sources of support, Teaching and Teacher Education, 87, 246-258 (2017)

20. A. Ruelens, I. Nicaise, Investigating a typology of trust orientations towards national and European institutions: A person-centered approach, Social Science Research, 87, (2020)

21. K. Gliske, J. Ballard, G. Buchanan, L. Borden, DF Perkins, The components of quality in youth programs and association with positive youth outcomes: A person-centered approach, Children and Youth Services Review, 120, (2021)

22. I.N. Odarich, M.I. Gavrilov, Competence-based approach in the higher education system, Baltic Humanitarian Journal, 6(1), 133-136 (2017)

23. V.I. Blinov, I.S. Sergeev, Blended learning models in vocational education: typology, pedagogical efficiency, implementation conditions, Vocational education and the labor market, 1(44), 4-25 (2021)

24. L.V. Bura, Formation of the professional identity of undergraduate students, Humanities, 3-51, 41-48 (2020)

25. M.A. Kunash, Approaches to the classification of individual educational routes of schoolchildren, Yaroslavl Pedagogical Bulletin, 2-3, 77-81 (2012) 